\title{
Book Review: Innovation in the Public Sector: Linking Capacity and Leadership. By Victor Bekkers, Jurian Edelenbros and Bram Steijn (eds) (2011). Basingstoke Palgrave MacMillan.
}

Book Review

Peter Robbins

Maynooth University

\section{Introduction}

Not quite oxymoronic but arguably a contradiction in terms; you rarely see the words public sector and innovation in the same sentence and definitely not as a book title. Innovation, as a concept, has become almost inseparable from private sector entrepreneurship, with the public sector generally perceived as a natural adversary of innovation. In fact, the concept of public sector innovation has been largely ignored in the academic field of public administration.

Hence, the rationale for this book is sound. This anthology of chapters edited by Bekkers, Edelenbos and Stejn addresses a gap in our literature and makes a significant contribution to setting a new research agenda for scholars interested in innovation. The story starts in Lisbon in 2000 when the EU agreed the Lisbon Strategy (also called the Lisbon Agenda). Its aim is to make the EU

'the most dynamic and competitive knowledge based economy in the world capable of sustainable economic growth with more and better jobs and greater social cohesion and respect for the environment by 2010.' (European Union, 2000).

Underpinning this vision, is the assumption that innovation is the engine of growth; that innovation is the necessary condition for creating a competitive economy that will facilitate commercial, social and environmental renewal.

A key belief is that economies can only prosper if the public sector has the capacity to develop into an innovative hub. A sophisticated level of creativity is required to deal with some of the societal challenges that beset the public sector, such as the quality of the health service; the quality of the education system; the fight against crime; the regeneration of socially and economically deprived communities or the development of a sustainable economy. This book explores some crucial themes in the context of innovation in the public service; it lucidly articulates what are the key differences between innovation in the private and public sectors.

A wealth of information has been gathered through research on innovation in the private sector; but the public sector, by comparison, remains largely uncharted territory in terms of what innovation is carried on there and how it is accomplished. Mulgan and Albury (2003) suggest that quality research in this area has been limited. Public institutions are often believed to be less innovative than private firms (Fuglsang and Pedersen, 2011) and yet there is little research to support the claim. Some research studies have, in fact, found the opposite - that the pubic sector is more innovative than the private (Earl, 2002; Koch et al., 2005). 
Advocates of the quality and complexity of public sector innovation often cite the Normandy landings on D-Day, an event that celebrated its $60^{\text {th }}$ anniversary in June 2014. The sea and air coordination of the surprise attack on the Normandy beaches is largely recognised as the most complex logistical operation ever to take place in world history and it was accomplished by the public sector. Similarly, the inventions of the Internet, or the moon landing, have emerged from public sector initiatives.

In business, however, the metrics around innovation are simpler, the north star of profit and growth acts to both guide and filter efforts. Simply, economic benefits are more important for private than public sector innovation (Fulsang and Pedersen, 2011). In the public sector, though, the stakeholders are more numerous and the considerations more complex.

'Whereas in the private sector, innovation just needs to be profitable to be worth doing, in the public sector, innovation must be about doing something worthwhile.' (Light, 1998)

Across the world, governments are under pressure to reduce their spending, and yet, demand for public services is increasing. The management of public service expenditure is increasingly characterised by trying to get 'more for less'.

\section{Public sector innovation - a contradiction in terms?}

Many argue that innovation in the public service is a contradiction in terms, suggesting that compared to the private sector, it is almost innovation free. There is some substance to this perspective and the supporting evidence usually rests on three key arguments. The most compelling is that the public sector lacks competition which, according to Schumpeter (1942), is an important pre-condition for innovation. Schumpeter asserts that innovation is simply an inevitable process of creative destruction as old industries and ways of doing things give way to new approaches, new industries, in a process which constitutes the cornerstone of any capitalist system.

But in the public sector, competition is rare. Borins (2001) notes that most public service organisations are monopolies and, hence, there is no pressure on them to innovate for competitive advantage. Governments enjoy a monopoly on the production of goods and services. Of course, in certain cases, there is a good reason for the monopoly, as it may have resulted from a market failure. However, the absence of competition creates an environment in which there is little incentive to improve, as there is no likelihood of poor performance resulting in closure, administration or even loss of earnings or employment for individual staff.

The second reason the public service is a difficult environment in which to encourage innovation is the bureaucratic culture that prevails there. A focus on process rather than outcomes, standardisation and formalisation, are the important values in the public sector, and these are hard to reconcile with differentiation and customisation, which are the hallmarks of the commercial sector. The public sector needs to provide legal security, stability, routine predictability and in doing this, they generally discourage individual freedom and risk-taking. Standardisation and process orientation are not fruitful conditions for innovation. Burns and Stalker (1961) found standardisation and formalisation to be forces for inertia in innovation.

The third impediment for innovation in the public service is the political nature of its administration. That it is rooted in a political democracy is perceived as a handicap for innovation. There are three reasons for this perception. First, politics is known as the art of compromise. Compromise is necessary when different stakeholders with different worldviews and different values converge to address a problem. Generally, such compromises are not innovative; rather they are incremental in character, as they inch along towards agreement using the 'science of muddling through' (Lindblom, 1959).

The second prong of this political handicap is the uniquely high perception of risk in this environment. Political cultures are perceived to be risk-avoiding cultures (Van Gunsteren, 1976). Innovation involves, by definition, a break from the routine and doing things differently. In a bureaucratic culture, political and public accountability are concepts with a high priority. There is, too, a sense that the media are hyper sensitive to the activities, policies and expenditures of politicians and public managers. The likelihood of public criticism of innovation arises on two levels (the latter possibly unfairly): first, if the project fails and, second, equally if the project succeeds. If the project succeeds, it is open to criticism for not having been done or thought of before. 
Consequently, there is little incentive to innovate where the context of risk is likely to outweigh any other factor. Borins (2001) has suggested that the public service reward system is asymmetric insofar as it punishes unsuccessful innovations far more than it rewards successful ones. Such an environment is hardly conducive to the risk taking that is warranted by innovation.

People in government fear nothing more than newsworthy failure... when new initiatives fail - and inevitably a large proportion do - they become highly newsworthy, with a focus on who is to blame. (Altshuler, 1997: 39)

This leads to the question of whether public office holders can ever persuade the media and the public that it is acceptable, in certain contexts and under certain conditions, to spend public money on something that ultimately turns out to be a failure.

Short-termism is the third factor mitigating against innovation in the public sector. Systematic innovation and entrepreneurship are proposed by Drucker (1985) as necessary pre-conditions for successful innovation. These involve orchestrating an array of people, ideas and resources in pursuit of innovation combined with a willingness to take acceptable risks to develop 'new combinations'. Investments in long-term capability building in research and development are examples of a long-term orientation that rarely exists in politics. Politics is characterised by shortterm orientation and is focussed on 'quick wins' intended to capture the hearts and minds of voters. For, people involved in projects connected with innovation, Pollitt (2011) suggests that the danger is that they will be instructed to innovate, congratulated when the first one goes well and then punished when the next one fails.

After this, new bureaucratic regulations will be imposed to prevent this type of failure from being repeated. Such cycles or alternations from tight to loose to tight controls again are well-known occurrences in public management. (Pollitt, 2011: 39)

\section{What's so different about the public service?}

Private sector innovation is generally, as noted above, motivated by profit or growth and, hence, the 'size of the prize' in terms of revenue and market share growth usually dictates the intensity of effort and the level of resourcing for key projects. Such innovation generally has as its output an artefact - a product, a solution or service that in the eyes of the innovator, meets an unmet or under-met need, either for a business, a specific market segment (like family holidays or a portable MP3 player, for instance), or an individual consumer. Just how good any individual organisation is at innovation, is often measured by the proportion of their turnover that is attributable to products or services launched in the prior three years: the higher the proportion, the better they are at innovation.

But, the public sector's agenda for innovation is set largely by societal challenges, such as the quality of the education system, the fight against crime, the development of a sustainable health service, the creation and delivery of an equitable welfare policy, the regeneration of economically and socially deprived cities and regions, the challenges of matching environmental policy with economic growth and in Ireland's case, the return to fiscal sovereignty.

These problems are very often 'wicked' in character, that is, not only are they difficult to solve, but they are also so complex, that they cannot even be easily defined. The way in which governments approach these problems has consequences, both for the problem being tackled, but also for the government and it's legitimacy. Governments are being confronted with a substantial crisis of authority. Other actors often take on their role in organising collective actions for collective challenges, like safe neighbourhoods, healthcare and sustainable environment. Thus, it is argued that there is a growing alienation between government and society. Such alienation can easily be detected in the results of, for instance, the Italian general election in March 2013 (where no coalition could be formed), and the UK local elections in May 2013, where the UKIP party won a historic level of representation. Echoes of this dissatisfaction were heard in the Irish European and local elections in May 2014, where half of the electorate voted for non-mainstream or 'protest' parties.

The collection is composed of nine separate chapters, sandwiched between an introduction and a conclusions or discussion chapter. The pieces include empirical, theoretical and conceptual chapters, completed by a final discussion. A range of topics is covered, including: innovation in small states (written for Scandinavia, but of special interest to Ireland), innovation in public procurement, case studies, health-care innovation, and two pieces on networks (intergovernmental and networks inside government itself). 
Rather than read the book as a single themed exploration, I think the chapters should be read in isolation, as each one opens up a new research agenda in a topic area, which has been long in need of such attention. This is a pioneering work in which there is much to think about and a great deal of good writing and subject matter to admire.

\section{About the reviewer}

Peter Robbins is Academic Director for the EDEN Centre for Entrepreneurship, Design and Innovation in Maynooth University. He is founder of a group called the Public Service Innovation Lab which links many of the managers charged with innovation for public sector and semi-state organisations in Ireland. He is a former Global Director of Innovation for GSK.

\section{References}

Altshuler, A.A. (1997). Public Innovation and Political Incentives, Ash Institute for Democratic Governance and Innovation, John F. Kennedy School of Government.

Borins, S. (2001). 'Encouraging innovation in the public sector'. Journal of Intellectual Capital, 2(3), 310-319

Burns, T and Stalker, G. (1961). The Management of Innovation, London: Tavistock University Press.

Drucker, P. (1985). Innovation and Entrepreneurship: Practice and Principles, New York: Harper and Row.

Earl, L. (2002). Innovation and Change in the Public Sector: a Seeming Oxy Moron - Survey of Electronic Commerce and Technology, Canada: Ottowa Statistics.

Fuglsang, L. and Pedersen, J.S. (2011). How Common Is Public Sector Innovation and How Similar Is It to Private Sector Innovation? Innovation in the Public Sector: Linking Capacity and Leadership, UK: Palgrave Macmillan.

Koch, P., Cunningham, P., Schwabsky, N. and Hauknes,
J. (2005). Innovation in the Public Sector; Summary and Policy Recommendations, Oslo: Public Report No. D24, NIFU STEP.

Light, P. (1998). Sustaining Innovation: Creating Non-Profit and Government Organizations That Innovate Naturally, San Francisco: Jossey-Bass Inc.

Lindblom, C.H. (1959). 'The science of muddling through'. Public Administration Review, 19(2), 7988.

Mulgan, G. and Albury, D. (2003). Innovation in the Public Sector, London: Strategy Unit Cabinet Office.

Pollitt, C. (2011). Contexts, Processes and Aspects of Innovation - Innovation in the Public Sector: Linking Capacity and Leadership, UK: Palgrave Macmillan.

Schumpeter, J.A. (1942). Capitalism, Socialism and Democracy, New York: Harper.

Van Gunsteren, H.R. (1976). The Quest for Control: A Critique of the Rational Central Rule Approach in Public Affairs, London: Wiley. 